\title{
Crisis, desposesión y mercado de trabajo en España: impactos en la Región Metropolitana de Madrid
}

\author{
Crisis, dispossession and labor market in Spain: \\ impacts on the Metropolitan Region of Madrid
}

Ricardo Méndez

\begin{abstract}
Resumen
Las áreas urbanas españolas han padecido una crisis que es global por su dimensión, pero tiene manifestaciones locales diversas y que ha afectado de modo intenso a sus mercados de trabajo. Los procesos de desposesión se reflejan en el fuerte crecimiento del desempleo, la precarización laboral, la devaluación salarial y una mayor desprotección de los trabajadores, que se concentran en aquellos sectores urbanos más vulnerables. El artículo ofrece una reflexión teórica sobre estas cuestiones y analiza lo ocurrido en la región metropolitana de Madrid en el contexto español mediante el uso de diferentes indicadores. También precisa las profundas desigualdades internas en el impacto de la crisis dentro de la aglomeración, que acentúan la segmentación territorial heredada y plantean nuevos retos.
\end{abstract}

Palabras clave: mercado de trabajo metropolitano; crisis; desposesión; vulnerabilidad urbana; Madrid.

\begin{abstract}
The Spanish urban areas have experienced a crisis that is global in its dimension but has different local manifestations. Such crisis has intensively affected the labor markets of these areas. Dispossession processes are reflected in the strong growth of unemployment, job insecurity, wage devaluation and less protection for workers, who are concentrated in the most vulnerable urban sectors. The article offers a theoretical reflection on these issues and analyzes what has happened in the metropolitan region of Madrid, in the Spanish context, by using different indicators. It also specifies deep internal disparities in the impact of the crisis within the agglomeration, which increase the territorial segmentation that has been inherited and pose new challenges.
\end{abstract}

Keywords: metropolitan labor market; crisis; dispossession; urban vulnerability; Madrid. 


\section{Introducción}

Los procesos de declive económico y deterioro de las condiciones de vida para buena parte de la población, junto al aumento de la desigualdad social y territorial provocada por la crisis iniciada en 2007 y profundizada por las políticas neoliberales de austeridad fiscal impuestas en la Unión Europea desde 2010, han tenido en España múltiples manifestaciones. El mercado de trabajo ha sido uno de los ámbitos donde el impacto ha sido más intenso, con la destrucción de varios millones de empleos, una creciente precariedad que se difunde hacia grupos profesionales y territorios que parecían inmunes, junto a una paralela devaluación salarial que polariza la pirámide laboral y aumenta la distancia entre sus extremos.

La crisis económica tuvo su origen en un proceso de financiarización que multiplicó los flujos de inversión en unos mercados globalizados y destinó buena parte de los mismos a potenciar un circuito secundario de acumulación ligado a la producción de espacio urbano como medio de lograr una elevada rentabilidad a corto plazo. Esas raíces urbanas de la crisis llevaran buena parte de sus efectos más negativos se concentren también en las ciudades, que muestran así la elevada vulnerabilidad acumulada durante la fase expansiva del ciclo inmobiliario.

Las aglomeraciones metropolitanas han mostrado en estos años una evolución contradictoria. Por una parte, concentran aquellas actividades y ocupaciones más intensivas en conocimiento que parecen haber resistido mejor los embates de la crisis, aunque sin evitar cierta precarización de los nuevos empleos generados. Al mismo tiempo, la inversión inmobiliaria - tanto residencial como empresarial - y la hipertrofia de la actividad constructora alcanzaron también en ellas elevados niveles, en paralelo a un fuerte incremento de los servicios al consumo como reflejo de una demanda que creció alimentada por la burbuja de crédito. Como resultado, las ventajas competitivas asociadas a las externalidades que genera la aglomeración no evitaron un notable empeoramiento de todos sus indicadores laborales y el aumento de la segmentación socio-espacial interna. En consecuencia, comprender los desiguales efectos laborales que la crisis ha generado en ellas exige dirigir la mirada algo más lejos y considerar de qué modo el proceso de globalización regido por una racionalidad neoliberal transformó sus mercados de trabajo e incrementó su exposición a un riesgo que se hizo evidente al agotarse el ciclo expansivo de la economía española.

El artículo tiene como objetivo proponer un esquema interpretativo sobre estas cuestiones para analizar luego los efectos de la crisis sobre el mercado de trabajo español y centrar su atención en la región metropolitana de Madrid. En su primer epígrafe, el texto propone una interpretación de la metamorfosis padecida por los mercados laborales en el capitalismo global, para considerar luego los fenómenos de desposesión que caracterizan las crisis capitalistas y por qué las diferentes áreas urbanas los padecen con desigual intensidad en relación con su grado de vulnerabilidad. El segundo apartado precisa la evolución del mercado de trabajo español desde 2007 en términos de actividad, ocupación y paro, calidad o precariedad del empleo, ingresos salariales, 
niveles de protección para los trabajadores y contrastes interurbanos observados. El tercero considera estos mismos aspectos en los municipios que superan los 25.000 habitantes dentro de la aglomeración madrileña y el efecto de la crisis en la creciente fragmentación del territorio metropolitano. En ambas escalas, la información procede de diferentes bases de datos publicadas por organismos públicos de ámbito estatal (Instituto Nacional de Estadística, Sociedad Pública de Empleo Estatal) o regional/autonómico (Instituto de Estadística de la Comunidad de Madrid). El artículo se completa con unas breves reflexiones finales sobre los retos a que se enfrentan mercados laborales como el madrileño y la necesidad de apostar por economías metropolitanas y modos de regulación que hagan compatible la recuperación del empleo con una sociedad y un territorio más inclusivos.

\section{Empleo, crisis capitalistas y vulnerabilidad metropolitana: una propuesta interpretativa}

Las grandes áreas urbanas españolas experimentan en las últimas décadas un conjunto de profundas transformaciones que han afectado tanto su economía como su organización social, sus formas de gobernanza o las dinámicas espaciales que modifican su morfología y sus relaciones con el entorno. Los mercados de trabajo no han sido ajenos a esa verdadera metamorfosis que hunde sus raíces en los procesos estructurales inherentes a la actual fase de desarrollo capitalista y que se manifiesta en muchas de sus actuales características. La crisis de ese modelo de acumulación iniciada en 2007 puso en cuestión algunos de esos rasgos y reforzó otros, provocando un deterioro general de las condiciones laborales que tuvo manifestaciones diversas según territorios, tal como propone la Figura 1, que sintetiza el argumento central para interpretar el caso analizado.

\section{La construcción de un nuevo modelo de relaciones laborales en el capitalismo global}

Tras la crisis del fordismo, uno de los rasgos estructurales que definió el periodo posterior fue la consolidación de un régimen de acumulación financiarizado (Chesnais, 2003), cuyos efectos desbordan el marco estrictamente económico para incidir también de forma directa sobre el sistema de relaciones laborales, transformando "el lugar que el trabajo ocupa en las sociedades salariales contemporáneas" (Alonso y Fernández, 2012, p. 13).

Por una parte, esto supuso una multiplicación sin precedentes de los flujos de capital, de los productos y los actores que operan en unos mercados financieros globalizados, con elevadas plusvalías que generaron unos excedentes en busca de inversión rentable y aparentemente segura. Un volumen creciente de ese capital se dirigió hacia un circuito secundario de acumulación (Harvey, 2007) que tiene en la producción de espacio urbano su principal motor y en las aglomeraciones metropolitanas uno de sus espacios de acción prioritarios, con tres tipos de efectos en el plano laboral. En primer lugar, la conversión del cluster inmobiliario- 
Figura 1 - Mercados de trabajo, crisis y vulnerabilidad metropolitana: una interpretación

\section{MERCADOS DE TRABAJO EN EL CAPITALISMO GLOBAL}

- Ciclos de inversión y volumen de empleo - Desregulación del mercado de trabajo

- Desindustrialización vs. construcción - Precarización del empleo (¿atípico?)

- Terciarización y dualización ocupacional - Segmentación de mercados laborales

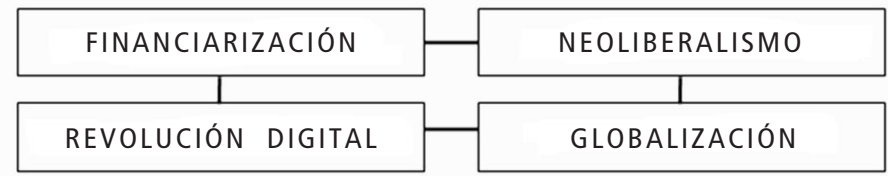

- Tecnologia y destrucción de empleos

- Nueva división internacional del trabajo

- Ocupaciones intensivas conocimiento

- Competencia de países emergentes

- Nuevas exigencias formativas

- Presión sobre condiciones de trabajo

\section{CRISIS ECONÓMICA Y DESPOSESIÓN}

\section{TRABAJADORES URBANOS}

- Pérdida del empleo/aumento del paro

- Precarización laboral

- Devaluación salarial

- Desprotección frente al desempleo

\section{ESPACIOS URBANOS}

- Depreciación de activos inmobiliarios

- Desahucios hipotecarios

- Privatización de viviendas sociales

- Privatización de espacios públicos

\section{VULNERABILIDAD Y DESIGUAL IMPACTO DE LA CRISIS}

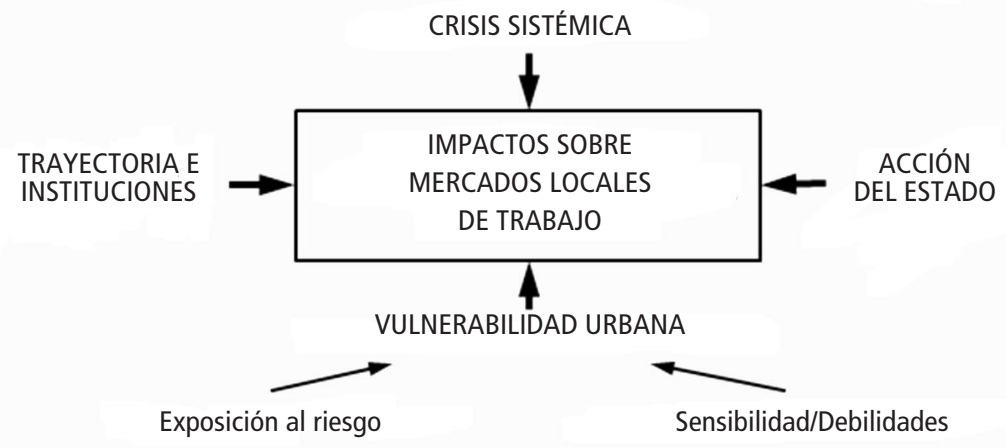

Fuente: Elaboración propia. 
-financiero en clave del crecimiento urbano incrementó la dependencia entre el volumen de empleo generado o destruido y los ciclos de inversión, acentuando el efecto provocado por las burbujas especulativas y su posterior estallido. En segundo lugar, esa reorientación de los flujos de capital aceleró los procesos de desindustrialización selectiva de los espacios metropolitanos y la creciente terciarización de su empleo, avanzando en una desmaterialización de sus economías (Halbert, 2005) alentada por una narrativa post-industrial que la considerada inevitable. Finalmente, la hiperespecialización en servicios propició también cierta dualización ocupacional, pues al tiempo que aumentó la presencia de trabajadores altamente cualificados en aquellos intensivos en conocimiento (servicios avanzados a las empresas, educación e investigación, sanidad, finanzas y seguros, servicios culturales y creativos...), cada vez más importantes en la redefinición de las jerarquías urbanas, aún creció más la de trabajadores poco cualificados en servicios destinados al consumo de la población o vinculados al turismo.

Al mismo tiempo, la difusión de la lógica financiera al conjunto de la economía, que aceleró la rotación del capital en lo que Sennett (2000) identificó como capitalismo del corto plazo, exigió una flexibilización de las relaciones laborales que la progresiva - aunque desigual según contextos institucionales - imposición de una racionalidad neoliberal hegemónica hizo posible (Peck y Theodore, 2010; Laval y Dardot, 2013). El objetivo de lograr la ruptura del pacto distributivo keynesiano, con un nuevo reparto del excedente entre trabajo y capital más favorable a este último, se materializó en una progresiva desregulación de los mercados laborales mediante reformas legislativas justificadas como medio de eliminar rigideces excesivas, que también afectaron a aquellos más regulados y sindicalizados como los de ámbito metropolitano.

Como reflejo del nuevo espíritu del capitalismo (Boltanski y Chiapello, 2002), que convierte la inseguridad laboral en rasgo consustancial a su lógica de funcionamiento (Beck, 2000), la precariedad se extendió bajo diversas formas (aumento de la contratación temporal y a tiempo parcial, de autónomos autoexplotados, empleo informal...), con un paralelo deterioro de la negociación colectiva (McDowell y Christopherson, 2009). Aunque más habituales en los servicios de baja productividad, las pequeñas empresas y los trabajadores menos cualificados, estas condiciones se difundieron también hacia aquellos otros segmentos más protegidos, como industrias y servicios intensivos en conocimiento, grandes empresas, ocupaciones más cualificadas y empleo público. Se acentuó así la segmentación entre un mercado de trabajo primario que acoge a aquellos trabajadores con contratos estables, mayor calidad del empleo, mejores retribuciones y derechos laborales, frente a un mercado secundario dominado por la precariedad, los bajos ingresos y una elevada incertidumbre, con el consiguiente efecto derivado sobre una mayor polarización social (Pratschke y Morliccio, 2012).

No pueden ignorarse tampoco las consecuencias de una revolución tecnológica que en el plano laboral mostró efectos ambivalentes. Por un lado, la rápida y masiva incorporación de las tecnologías de 
información y comunicación al campo de la automatización industrial o la gestión supuso una destrucción de empleos que animó a algunos analistas a proclamar un prematuro fin del trabajo (Rifkin, 1996). Como contrapunto, la difusión de las tecnologías digitales incrementó el valor añadido asociado a tareas de producción inmateriales, con nuevos empleos mayoritariamente concentrados en las aglomeraciones metropolitanas que presentan a menudo exigencias formativas y de cualificación específicas. Esas mismas herramientas tecnológicas, que hicieron posible un modelo productivo más flexible y segmentado, facilitaron la externalización y subcontratación de tareas y productos en territorios con menores costes y controles que los metropolitanos, con el consiguiente traslado y fragmentación de los grandes centros de trabajo (Wills, 2009).

Finalmente, la creciente globalización de mercados y procesos impulsó una nueva división internacional del trabajo con efectos evidentes en las metrópolis europeas. A la cada vez mayor competencia de las empresas ubicadas en países emergentes en determinados segmentos productivos se sumó la presión ejercida por inversores y accionistas para aumentar sus beneficios a costa de una deslocalización total o parcial, reduciendo la capacidad negociadora de los trabajadores metropolitanos para mantener sus anteriores condiciones de trabajo ante esa amenaza.

En resumen, antes de que se desencadenase la Gran Recesión en 20072008, los mercados de trabajo metropolitanos eran ya muy distintos a los que caracterizaron el periodo fordista-keynesiano. La confluencia de factores económicos, tecnológicos, institucionales y sociales fue la clave de esa transformación. Pese al crecimiento del empleo en la fase expansiva del ciclo económico y la mayor presencia de sectores y empleos cualificados en este ámbito, la fragilidad derivada de la segmentación laboral y espacial, junto al aumento del trabajo contingente o precario, estuvieron en el origen de una creciente vulnerabilidad que se hizo patente con el inicio de la crisis, aunque con efectos netamente distintos según grupos sociolaborales y territorios.

\section{De la desposesión al desigual impacto territorial de la crisis}

Un componente esencial en el proceso de financiarización de las economías metropolitanas, canalizador de flujos de inversión hacia el sector inmobiliario, es un mercado hipotecario que, progresivamente desregulado, alcanza una importancia central en la estrategia de los operadores financieros. Su protagonismo en la formación de burbujas especulativas y en su posterior crisis, al saturarse la demanda solvente para unos inmuebles sobrevalorados, elevarse las tasas de interés y crecer la morosidad, ha sido ampliamente estudiado y está en el origen de las crisis financieras (Aalbers, 2008; Daher, 2013). La titulización de las hipotecas y el aumento en el grado de apalancamiento de las entidades financieras en ausencia de controles estrictos tienden a ampliar y difundir el riesgo provocado por ese endeudamiento masivo hasta hacerlo sistémico. De este modo, el auge y la caída de los mercados hipotecario e inmobiliario son fases orgánicamente 
entrelazadas de unos ciclos de acumulación y posterior desposesión que se suceden de forma periódica en momentos y lugares diversos.

En ese sentido, "el papel continuo y persistente de las prácticas depredadoras" en los procesos de acumulación ya fue destacado por Harvey (2004, p. 116) como rasgo inherente a la lógica capitalista a lo largo de su historia. Aunque la desposesión es un fenómeno peermanente, alcanza sin duda su mayor intensidad en los momentos de crisis o ruptura con la lógica de acumulación anterior. Es entonces cuando la destrucción de capacidad productiva y empleo, la depreciación de los activos financieros e inmobiliarios, la privatización de bienes públicos o las transferencias de propiedad en detrimento de quienes perdieron su trabajo, sus ahorros, o quedaron atrapados en la trampa de la deuda genera unos costes sociales muy elevados. Tanto los sectores populares como buena parte de las clases medias urbanas padecen así un deterioro de su situación derivado de diversas formas de desposesión que a menudo se suman (Figura 1).

Por una parte, la desposesión se hace patente en el plano laboral y afecta a quienes pierden su empleo y pasan a formar parte del colectivo de trabajadores desechables (Bales, 2000) o superfluos, excluidos de un mercado con oferta laboral excedentaria. Pero también a quienes, ante la presión que supone el riesgo de perder el empleo y la dificultad para recuperarlo, aceptan condiciones de trabajo más inestables, contratos a tiempo parcial, salarios más bajos, empleos informales, etc., que acentúan los niveles de precariedad preexistentes. El aumento de la población desempleada y las limitaciones presupuestarias de los organismos públicos también provocan la desprotección de amplios colectivos, que ven aumentar así el riesgo de pobreza y exclusión.

Por otra parte, la desposesión se hace también visible en el espacio urbano construido y en el acceso al mismo de determinados grupos sociales. La depreciación generalizada del patrimonio inmobiliario de unas familias que en muchos casos deben seguir haciendo frente a hipotecas por un importe muy superior a su actual precio de mercado, junto a los desahucios de viviendas provocados por el impago de esas deudas hipotecarias o de alquileres, son sus principales manifestaciones. La venta de viviendas sociales a fondos de inversión, o la privatización de determinados espacios públicos por parte de gobiernos locales con la excusa de obtener recursos adicionales resultan, en ocasiones, una forma complementaria de desposesión colectiva a la que se une el deterioro de los servicios sociales y asistenciales, contribuyendo también a la transferencia de propiedad y poder.

No obstante, la intensidad de los fenómenos de desposesión resulta muy diferente no sólo entre grupos sociales, sino también entre territorios. Por ello puede hablarse con pleno sentido de una geografía de la desposesión que se hace visible a diversas escalas espaciales, afectando más a unas aglomeraciones metropolitanas o ciudades que a otras y concentrando su mayor intensidad en algunos sectores o barrios de su interior, mientras en otros esas situaciones tienen mucha menor importancia.

La evidencia de esos contrastes exige considerar la influencia de los factores locales en el desigual impacto que las crisis tienen sobre los mercados de trabajo (Figura 1), 
complementando las visiones estructuralistas con otros enfoques como los institucionales (Bathelt y Glückler, 2013). Así, junto a la indudable influencia de unos procesos estructurales que resulta común a todo tipo de ciudades, la acción del Estado matiza esos efectos en función del marco legislativo o los tipos de políticas aplicadas. Pero a eso se añaden unas trayectorias e instituciones locales heredadas en cada lugar (valores, comportamientos culturales, convenciones, organizaciones) que responden de forma específica a ese nuevo contexto, lo que permite confirmar la existencia de múltiples geografías locales para una crisis de dimensión global (Martin, 2011).

Desde esa perspectiva, un factor clave de las nuevas desigualdades espaciales será el grado de vulnerabilidad mostrado por las diferentes áreas urbanas (Alguacil et al., 2014). Pueden definirse como vulnerables aquellas ciudades o barrios con alta probabilidad de verse afectados en forma negativa por algún acontecimiento o proceso de origen externo - como una crisis económica - en función de dos tipos de razones. Por un lado, una elevada exposición a riesgos de diversa naturaleza que escapan a su control; por otro, su escasa capacidad de respuesta, tanto por sus debilidades internas como por la falta de apoyo externo para atenuar los daños provocados.

La vulnerabilidad urbana tiene un carácter relativo, pues todos los lugares son hasta cierto punto vulnerables pero en distinto grado y según el tipo de amenaza a que se enfrenten. Es también dinámica, pues aunque se asocia con frecuencia a problemas estructurales y persiste con el paso del tiempo, puede aumentar o disminuir en relación con decisiones y acciones llevadas a cabo por actores públicos o privados y acumuladas a lo largo de su trayectoria. Es, asimismo, una construcción social o una incertidumbre fabricada, por lo que aquellas áreas urbanas que optaron por modelos de crecimiento de alto riesgo, excesivamente especializados en lo económico, polarizados en lo social e insostenibles en lo ambiental, serán más vulnerables. No puede olvidarse, por último, su dimensión política, lo que equivale a afirmar la importancia del modelo de urbanización neoliberal como productor de vulnerabilidades (Hidalgo y Janoschka, 2014).

Entendida así, la diferente vulnerabilidad de las aglomeraciones metropolitanas y/o de los núcleos que las integran frente al deterioro de sus mercados de trabajo puede interpretarse, en primer lugar, como resultado de su previa exposición al riesgo. En aquellos casos donde la financiarización y el crecimiento inmobiliario con el consiguiente endeudamiento de familias y empresas - alcanzaron mayor desarrollo, junto con una expansión de servicios al consumo de baja productividad y generadores de un empleo muy precario, el crecimiento económico y del empleo en la fase alcista del ciclo se verá luego contrarrestado por una destrucción de puestos de trabajo de similar intensidad. Por el contrario, aquellos otros que mantuvieron una mayor diversificación económica, con más presencia de la industria y de servicios necesitados de mayor cualificación, generadores también de mejores empleos, resultarán menos vulnerables ante la crisis (Méndez, Abad y Echaves, 2015).

Pero en el interior de esos espacios metropolitanos, la concentración de los grupos laborales más débiles en determinados 
espacios como resultado de una lógica mercantil que propició una creciente segmentación, tenderá a concentrar en ellos los mayores impactos negativos sobre el mercado de trabajo. La destacada presencia de ambos tipos de situaciones en unas áreas metropolitanas que reúnen a los extremos de la pirámide laboral puede explicar una evolución global a menudo menos favorable que la de determinadas ciudades medias con menores contrastes internos.

Se ha señalado que "la crisis económica que atravesamos se suma a un cambio mucho más profundo, de distintas temporalidades y dimensiones" (Subirats y Martí-Costa, 2014, p. 137). Puede entonces afirmarse que los mercados de trabajo metropolitanos aún muestran cierta continuidad con su pasado reciente, pues la huella de la globalización neoliberal sigue presente. Pero, al mismo tiempo, la crisis ha supuesto discontinuidades y contradicciones que han abierto nuevas brechas que se suman a las anteriores. Tras una panorámica sobre los intensos efectos de la crisis en el mercado de trabajo español, la aproximación al caso de Madrid puede concretar algunas de esas tendencias.

\section{Impactos de la crisis sobre el mercado de trabajo en España}

Todas las crisis capitalistas provocan la destrucción de puestos de trabajo, un proceso que en el caso español registra - de forma recurrente - especial intensidad. El deterioro de la calidad del empleo que permanece y el incremento de los sectores sociolaborales desprotegidos son el complemento de lo anterior y esa doble perspectiva puede orientar el comentario sobre las tendencias más destacadas de estos últimos años.

\section{Ciclo económico y desempleo en España: algunas evidencias}

Con la crisis del modelo de producción fordista que tuvo lugar en los años 70 del pasado siglo y ante la imposibilidad de mantener una emigración exterior que había servido como válvula de escape para el déficit crónico de empleo, la tasa de paro ya alcanzó en España el 21,9\% en 1985 y llegó al 22,4\% en 1993 , tras la crisis financiera internacional al inicio de esa siguiente década. A partir de esa fecha, el modelo de crecimiento económico que - en un contexto internacional expansivo - tuvo como factor clave la alimentación de una enorme burbuja crediticia e inmobiliaria permitió generar ocho millones de nuevos empleos entre 1995 y 2007 hasta alcanzar una cifra de 20,7 millones de ocupados, con una tasa de paro del 8,6\% según datos de la Encuesta de Población Activa.

Ese crecimiento de la ocupación se produjo en todos los sectores de actividad y fue máximo en los servicios, que al finalizar la fase expansiva del ciclo económico concentraban ya dos de cada tres empleos (hasta el $76 \%$ al finalizar 2014). Pero en términos relativos resultó aún mayor en el sector de la construcción, donde se generaron 1,5 millones de ocupaciones en esos doce años (de 1,2 a 2,7 millones) hasta alcanzar un 13,5\% del empleo total en 2007, muy por encima de su importancia relativa en el resto de países 
europeos y en niveles ya próximos a los del empleo industrial $(16,0 \%)$.

La saturación de la demanda solvente en el mercado inmobiliario y el consiguiente aumento de los inmuebles vacíos, la subida de tipos de interés para las hipotecas, junto a una restricción del crédito que se agravó con la crisis financiera internacional en el otoño de 2008 puso fin a los años en que la tasa de crecimiento en España duplicaba la del promedio de la Unión Europea (Figura 2). En tan sólo dos años la cifra de ocupados se redujo en casi dos millones de personas, de los que más de la mitad correspondió a trabajadores de la construcción. Tras una relativa estabilización de esos valores por las políticas de corte neokeynesiano destinadas a generar empleo, a partir de 2010 la imposición de un ajuste estructural de inspiración neoliberal como respuesta a la crisis de la deuda provocó una segunda recesión, que en los tres años siguientes destruyó otros 1,8 millones de empleos, con una moderada recuperación a partir de esa fecha y un total de 17,5 millones de ocupados al finalizar el año 2014.

En términos comparativos, cuatro de cada diez empleos perdidos en la UE se localizaron en España, que mostró de nuevo la

Figura 2 - Ocupación, desempleo y tasa de paro en España, 2001-2014

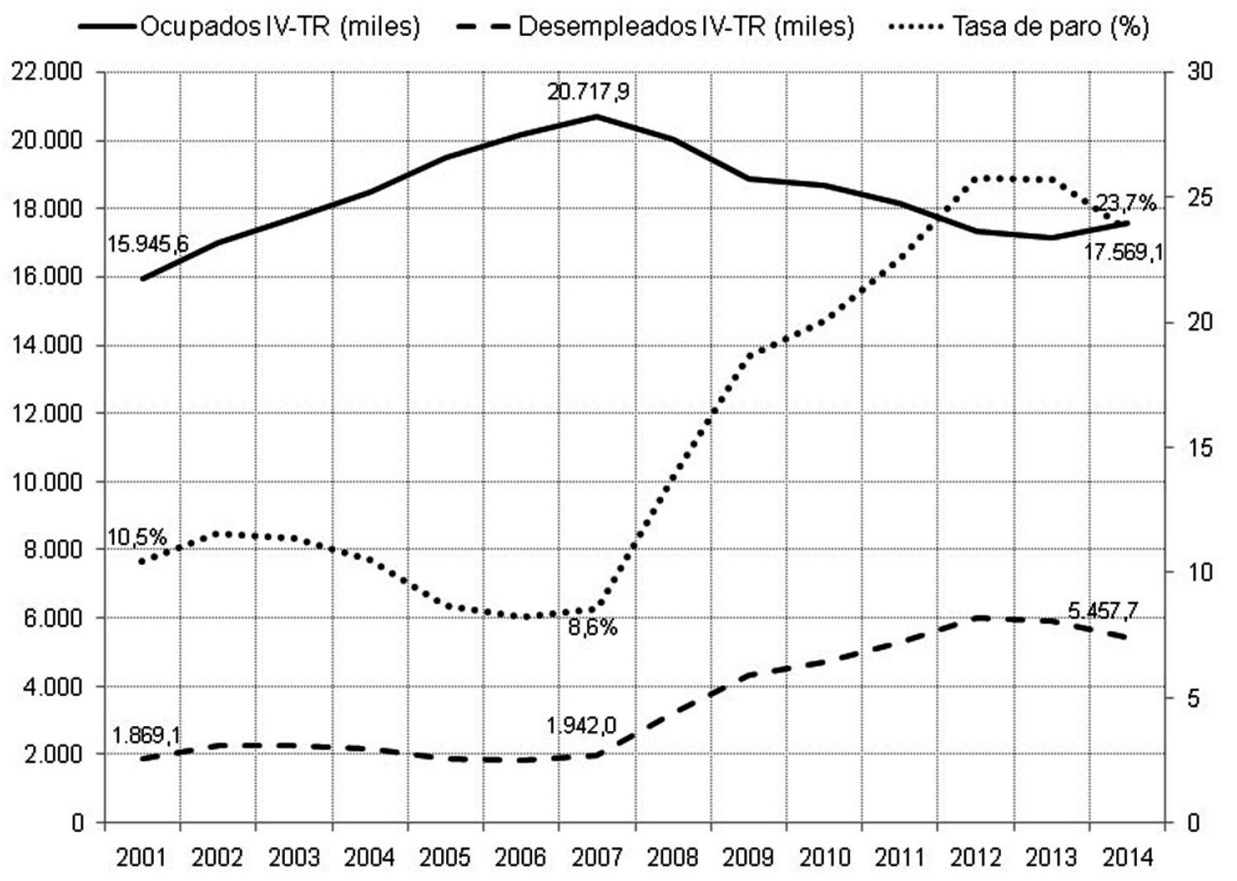

Fuente: Instituto Nacional de Estadística. Encuesta de Población Activa (4º trimestre). 
elevada sensibilidad de un mercado de trabajo donde la elevada presencia de actividades con baja productividad, muy dependientes del consumo interno y del ciclo económico, acentuó la intensidad del impacto. Resultan, en cambio, cuestionables las tesis que culparon del proceso a la supuesta rigidez del mercado laboral español para justificar así sucesivas reformas laborales, pues con una misma legislación laboral pudieron generarse y destruirse varios millones de puestos de trabajo, sin lograr en ningún caso prevenir o limitar la siguiente crisis de empleo (Recio y Banyuls, 2011).

Pero el coste social del proceso se intensificó al seguir creciendo en esos años la población activa, tanto por la incorporación de jóvenes y mujeres al mercado laboral como por un saldo migratorio positivo que sólo cambió de signo desde 2013, cuando la falta de oportunidades incrementó los movimientos de retorno junto a la emigración de jóvenes españoles cualificados. Su resultado fue el aumento del número de desempleados desde 1,9 millones al terminar 2006 hasta superar los 6 millones en 2013 y reducirse a 5,5 millones en el cuarto trimestre de 2014 como reflejo de una recuperación aún incipiente. Más grave es constatar que el paro de larga duración creció aún con mayor intensidad y las 223.800 personas que en 2007 llevaban en esa situación más de dos años llegaron a 2,4 millones al final del periodo analizado, con los consiguientes procesos de exclusión social asociados.

En consecuencia, la tasa oficial de paro volvió a superar el $25 \%$ de la población activa en 2012-13, con una leve reducción posterior
(23,7\% al finalizar 2014), por la creación de nuevo empleo y el descenso de los activos. Aunque el empleo informal puede moderar el impacto social de esas cifras, los incentivos fiscales a las empresas para regularizar a sus trabajadores hacen que ese fenómeno se relacione más con profesionales que no declaran fiscalmente toda su actividad que con la presencia de grandes bolsas de trabajo sumergido, salvo en sectores específicos, como agricultura, hostelería, servicio doméstico. Pero el grado de exposición a esa forma de desposesión ha sido muy desigual según grupos sociales, acentuando algunas diferencias previas (Figura 3).

Así, por ejemplo, la tasa de paro de los trabajadores con nacionalidad española se multiplicó por 2,8 hasta situarse en el $22,4 \%$, aún bastante inferior al 33,2\% de los inmigrantes extranjeros. Respecto al nivel formativo, la población analfabeta o sin estudios triplicó su cifra inicial hasta el 56,3\%, mientras los titulados superiores la sitúan en el $14,3 \%$, aunque duplicando ampliamente su nivel inicial. No obstante, es entre los jóvenes donde la dificultad para integrarse en el mercado laboral alcanza valores insostenibles, con tasas del $48,9 \%$ de paro en el grupo de 20 24 años y hasta del $67,3 \%$ en el de 16-19 años. Finalmente, el desempleo comenzó afectando sobre todo a los hombres (construcción, industrias auxiliares...), pero las políticas de austeridad difundieron su impacto a mujeres trabajadoras en servicios sociales, comercio minorista y otros servicios a la población, lo que justifica que su tasa de paro $(24,7 \%)$ aún sea superior a la masculina $(22,8 \%)$. 
Figura 3 - Desempleo y crisis en España: un desigual impacto social (2006-2014)

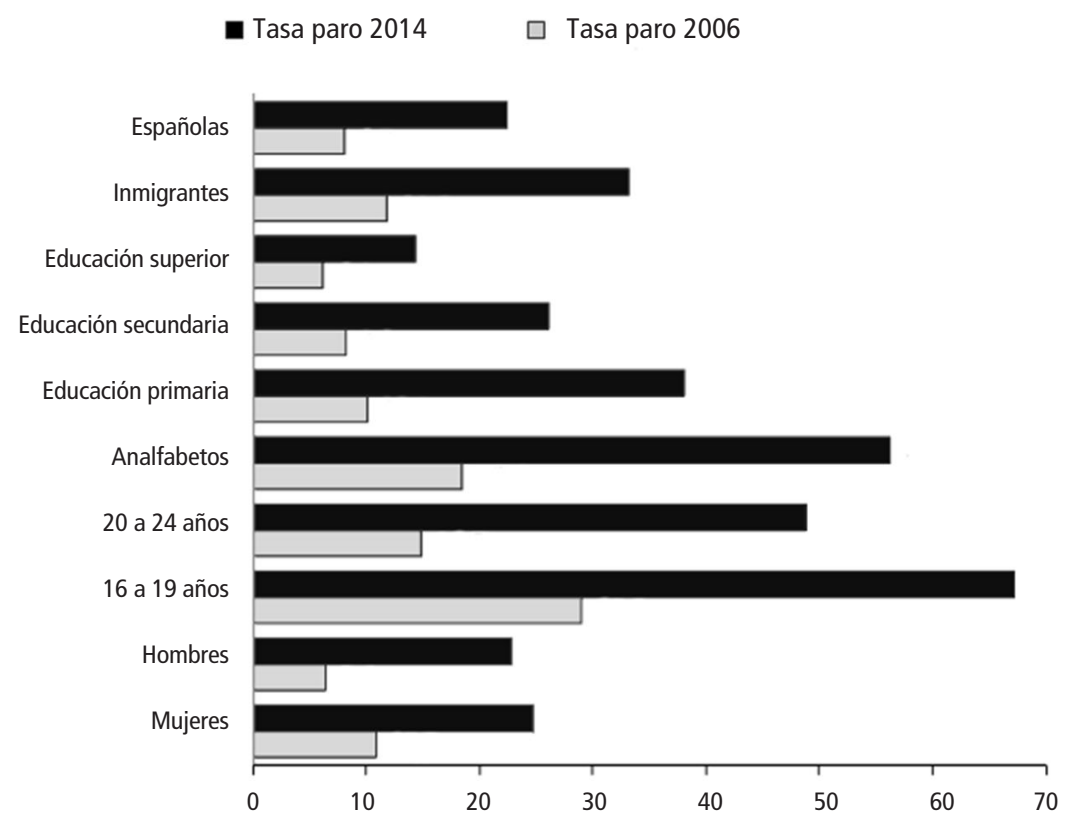

Fuente: Instituto Nacional de Estadística. Encuesta de Población Activa.

\section{Precariedad laboral y desprotección social: los nuevos pobres}

Desde el inicio de la crisis, en España se han aprobado dos nuevas reformas laborales flexibilizadoras (2010 y 2012) que se suman a las cinco anteriores legisladas desde 1984, generadoras de varios efectos acumulativos. Por un lado, han normalizado las diversas modalidades de contratos precarios hasta convertir en inadecuada la denominación de empleo atípico que aún se les otorga. Por otro, redujeron las indemnizaciones por despido para los contratos indefinidos bajo el supuesto de atenuar la dualidad del mercado laboral limitando los derechos asociados al empleo estable. Por último, redujeron la capacidad negociadora de los sindicatos al dar prioridad a los contratos de empresa sobre la negociación colectiva.

La presión ejercida por el elevado y prolongado desempleo, junto con el efecto de estas reformas legislativas destinadas a reforzar la asimetría en la relación capital-trabajo, se reflejan en tres tipos de consecuencias especialmente significativas.

- La temporalidad en la contratación no es resultado de la crisis sino anterior a ella e inherente al modo de regulación neoliberal. Ya en 2006 más del 88\% de los contratos firmados en España tuvieron ese carácter y la crisis sólo ha cronificado la situación, aumentando esa proporción en 2014 al 91,9\%. Pero ese indicador de flujo debe complementarse con 
otro de stock para adquirir pleno sentido. Así, de los ocupados en el último trimestre de 2006 una tercera parte $(33,7 \%)$ tenían un contrato temporal (5,6 millones) por dos tercios con contrato indefinido (11,0 millones); en el mismo trimestre de 2014, los ocupados con contrato indefinido son prácticamente el mismo número, mientras la destrucción de empleo se concentró en los trabajadores temporales cuyo volumen se redujo a 3,5 millones, apenas una cuarta parte $(24,2 \%)$ del total. Además, se sustituye empleo a tiempo completo por otro a tiempo parcial $(10 \%$ de los contratos indefinidos y $32 \%$ de los temporales), resultado más de la falta de alternativas que de la voluntad de los trabajadores por compatibilizar la vida laboral y personal (Servicio de Estudios Fundación $1^{\circ}$ de Mayo, 2014a). Su consecuencia es la difusión de trayectorias laborales discontinuas, marcadas por la inseguridad crónica, los bajos ingresos y la ausencia de perspectivas de mejora, asimilables al actual concepto de precariado (Standing, 2013).

- Lo que sí es efecto de la crisis y de la reforma laboral de 2012 es la devaluación salarial que, con el argumento de reducir costes y elevar la competitividad de la economía española, ha incrementado los excedentes empresariales, provocando una transferencia de rentas que cuestiona los mecanismos redistributivos y la cohesión social. Desde 2011 a 2014 los salarios reales tuvieron una evolución negativa todos los años, con un retroceso acumulado del -7,2\% y el consiguiente aumento de los trabajadores pobres, aquellos que pese a disponer de un empleo formal tienen unos ingresos inferiores al $60 \%$ de la mediana de renta. Pese a la escasez de datos disponibles, un informe de Eurostat con cifras de 2012 elevaba su número al 12,3\% de los ocupados en España, sólo por detrás de Rumanía y Grecia dentro de la UE (Servicio de Estudios F1M, 2014b).

- A lo anterior debe sumarse que la prolongación del paro y las restricciones presupuestarias han limitado el número de desempleados que cobran algún tipo de prestación. Aquí se incluyen tanto las prestaciones contributivas percibidas por quienes cotizaron a la Seguridad Social durante un periodo mínimo establecido, como las asistenciales - de menor cuantía y duraciónpara quienes no cumplen esos requisitos. En los años anteriores al estallido de la crisis su número se mantuvo estable y ligeramente por encima del millón de beneficiarios, con una tasa de cobertura creciente pero inferior al $70 \%$. El brusco cambio de coyuntura hizo que los 1,4 millones de beneficiarios en 2007 crecieran hasta los 3,0 millones de 2010, con una tasa de cobertura del $78,4 \%$. Pero desde esa fecha el incremento de quienes superaron el plazo máximo de dos años de prestación ha reducido en medio millón el número de beneficiarios en 2014, con una tasa de apenas el 59\%. Al mismo tiempo, si las prestaciones contributivas representaban el $60 \%$ del total en 2010 , apenas alcanzan el $42 \%$ en 2014 , lo que equivale a una reducción de los ingresos percibidos, ahondando así la desposesión de quienes fueron expulsados del mercado laboral y, sin alternativas, atravesaron el umbral de la pobreza. 


\section{Una desigual vulnerabilidad urbana frente a la crisis: la evolución del desempleo}

Hace dos décadas Robert Castel afirmaba que "empieza a estar claro que la precarización del empleo y el desempleo se han inscrito en la dinámica actual de la modernización. Son las consecuencias necesarias de los nuevos modos de estructuración del empleo y la lucha por la competitividad, que convierten en sombra a gran parte del mundo" (Castel, 1997, p. 406). La crisis ha acentuado esa tendencia, pero tanto el comportamiento de las ciudades como de sus barrios frente al deterioro laboral ha sido muy desigual, contribuyendo así a dibujar esa nueva geografía de la desposesión ya mencionada. Un comentario sobre la evolución del paro registrado en los municipios españoles que superan los 20.000 habitantes aporta claves explicativas de esas diferencias interurbanas (Méndez, 2013).

Así, aunque todas esas ciudades padecieron un aumento de los excluidos del mercado de trabajo, en ocho casos la tasa de crecimiento en 2006-2014 superó el 350\% y en otros cincuenta y siete el $200 \%$, mientras fueron setenta y cuatro las que no llegaron a duplicar su volumen inicial de paro y en cuatro de ellas el crecimiento resultó inferior al 50\%, con diferencias de uno a diez entre los valores extremos registrados. Pero, además, "resulta muy difícil sostener el argumento sobre la rigidez del mercado de trabajo como factor determinante del mayor impacto de la crisis sobre el empleo en España cuando los datos empíricos ponen de manifiesto que - existiendo un único marco de legislación laboral para el conjunto del Estado - la intensidad de dicho impacto ha sido notablemente diferente a nivel territorial" (Rocha, 2010, p. 26). No obstante, son las regularidades observables en el mapa (Figura 4) las que permiten deducir los principales factores explicativos de esa desigualdad.

Si hace tres décadas la crisis del fordismo provocó un fuerte incremento del paro en las ciudades industriales, mineras o portuarias del Eje Atlántico (del País Vasco a Galicia, en el norte, junto a Andalucía occidental), mientras las del Eje Mediterráneo (este) o Madrid mostraban una evolución más favorable, ahora la situación parece invertirse. Tanto el mayor tamaño de los círculos como su tonalidad más oscura reflejan que la mayor parte de las ciudades con tasas de crecimiento superiores al $200 \%$ se localizan en el Eje Mediterráneo, convirtiendo a estas regiones (Comunidad Valenciana, Murcia, Andalucía oriental) en las de mayor destrucción de empleos. En todos estos casos se trata de ciudades con una fuerte especialización turístico-residencial y un excesivo peso del cluster inmobiliario, así como de un amplio conjunto de servicios al consumo que sufrieron el efecto de la crisis financiera y la paralización del mercado hipotecario, destruyendo con rapidez un empleo de muy baja calidad asociado a ese modelo de crecimiento sin apenas innovación. Algunas ciudades interiores que apostaron por una urbanización intensiva y actividades como la logística, afectada por la retracción del consumo interno, registraron una evolución similar. A esas áreas de máximo impacto hay que sumar algunos municipios de la región metropolitana de Madrid - en el centro de la 
Figura 4 - Crecimiento del desempleo en municipios con más de 25.000 habs., 2006-2014

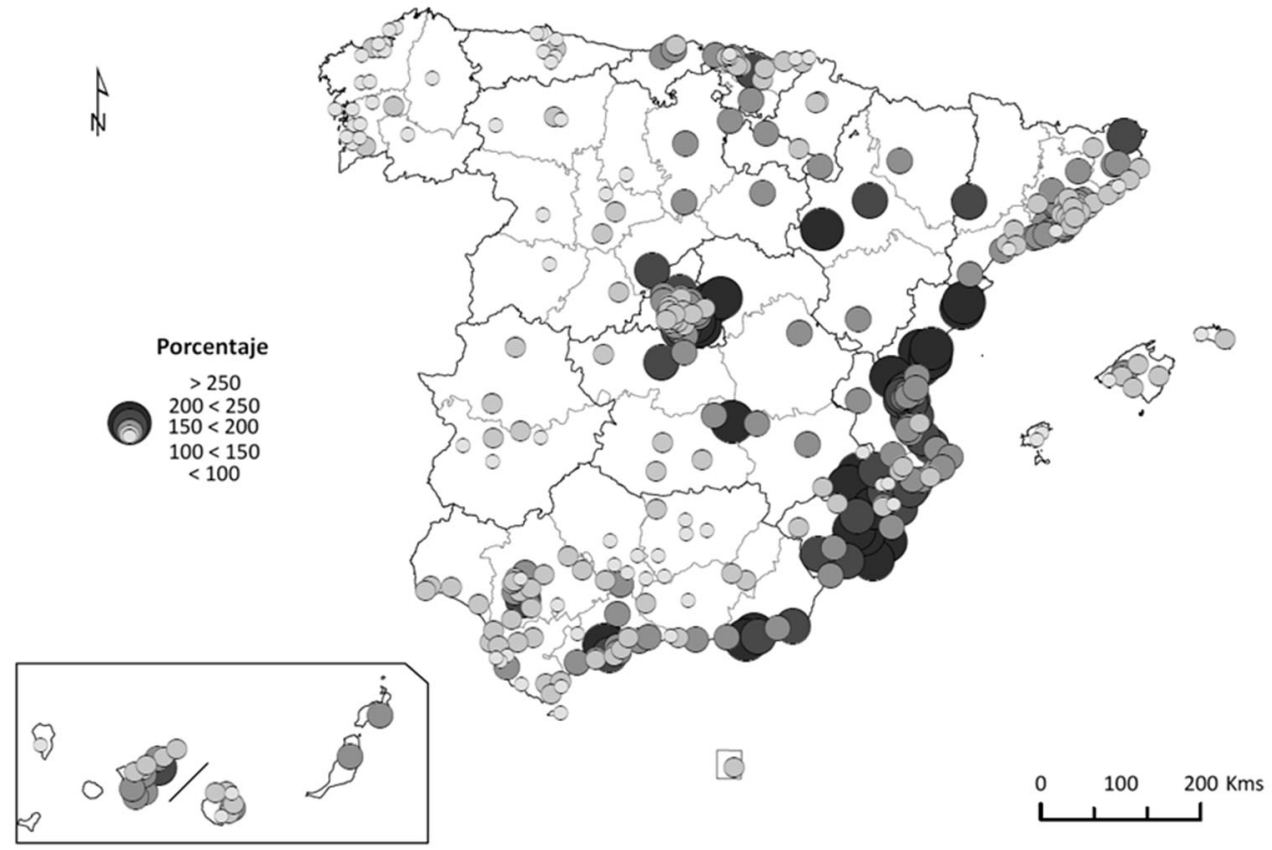

Fuente: Sociedad Pública de Empleo Estatal. Movimiento Laboral Registrado.

península Ibérica - y su periferia externa, en contraste con crecimientos muy inferiores en otros municipios de la aglomeración, poniendo así de manifiesto unas contradicciones internas que serán abordadas en el siguiente epígrafe.

El contrapunto a esta situación se encuentra en otro conjunto de ciudades españolas que sufrieron un impacto más moderado, sin duplicar en esos años su cifra de desempleados. Casi la mitad se localizan en el Eje Atlántico, donde una parte de sus antiguas ciudades industriales ha diversificado su economía, manteniendo cierta actividad industrial renovada que generó demanda para servicios a las empresas que se suman al crecimiento reciente de aquellos otros ligados a la distribución comercial, la cultura o el ocio. Eso también ha ocurrido en un número significativo de ciudades medias del interior peninsular, mientras en estas regiones también son numerosas las capitales administrativas o los centros de servicios con escaso dinamismo, que no registraron altas tasas de crecimiento durante los años de la burbuja inmobiliaria y luego tampoco padecieron los efectos de su crisis. 


\section{Crisis y mercado de trabajo en la región metropolitana de Madrid}

La región metropolitana de Madrid, que en términos administrativos se identifica con una de las 17 Comunidades Autónomas en que se estructura el territorio español, constituye la tercera aglomeración urbana europea por población (6,5 millones de habitantes), con un rango funcional similar por su volumen de producción y empleo, presencia del sector financiero y de servicios intensivos en conocimiento, conectividad a las redes de comunicación internacionales, o capacidad de consumo (Sánchez Moral, 2011). ${ }^{1}$ Su proceso de inserción en la globalización capitalista se reflejó en una sucesión de fases de intenso crecimiento y declive que han puesto en evidencia el riesgo asociado a una racionalidad neoliberal generadora de elevada vulnerabilidad.

\section{Madrid, del crecimiento a la crisis}

Por una parte, Madrid conoció un periodo de expansión desde la última década del pasado siglo y hasta 2007, con elevadas tasas de crecimiento económico y capacidad para atraer inversiones, empresas e inmigrantes internacionales, hasta situarse entre los territorios supuestamente ganadores del proceso. En un informe publicado inmediatamente antes de iniciarse la profunda crisis que ha marcado estos últimos años, los expertos de la OCDE señalaban que "el área metropolitana de Madrid ha alcanzado un alto nivel de competitividad durante la última década, pues de ser una capital con una función central en España, pero relativamente aislada del resto de Europa, Madrid se ha convertido en un destacado centro de poder dentro de la economía global", llegando a afirmar que eso se debía a haber "capturado los beneficios de la globalización" (OCDE, 2007, p. 15).

En el plano laboral, entre 1996 y 2006 la población ocupada aumentó en 1,2 millones (de 1,8 a 3,0 millones) gracias a una afluencia masiva de inmigrantes extranjeros, con un crecimiento del $70 \%$, muy superior a las restantes metrópolis europeas. Como contrapunto, el número de desempleados se redujo en 231.000 (de 441,6 a 210,5 miles) y la tasa de paro descendió del $19,8 \%$ al $6,5 \%$, aunque con valores superiores en el caso de las mujeres $(8,8 \%)$, inmigrantes $(9,4 \%)$ o jóvenes menores de 25 años $(17,4 \%)$.

Dentro del territorio metropolitano, el menor dinamismo en la creación de empleo correspondió a los antiguos núcleos industriales y obreros del sur y del este, donde el progresivo declive de esas actividades sólo fue sustituido por la implantación de grandes áreas logísticas y comerciales generadoras de un empleo de baja calidad. Por el contrario, buena parte de los servicios intensivos en conocimiento se localizaron en la ciudad de Madrid y en los núcleos metropolitanos del norte y oeste, tradicionalmente residenciales, con un perfil profesional más cualificado y población de mayor renta, lo que profundizó la segmentación social y espacial en el interior de la aglomeración (Méndez, Ondátegui y Sánchez Moral, 2007). 
No obstante, la evolución del mercado de trabajo madrileño en ese periodo también reflejó una serie de fragilidades que cobrarían pleno significado en años posteriores. En cuanto a la estructura sectorial de la ocupación, acentuó la hipertrofia de unos servicios que aumentaron en más de un millón su volumen de empleo hasta representar el $77,2 \%$ del total metropolitano (71,8\% en 1996), frente a una paralela desindustrialización (del 18,0\% al $11,2 \%)$ que afectó a todo tipo de actividades, con un aumento bastante mayor del comercio, la hostelería y los servicios a la población (51\% del empleo total metropolitano en 2006), con empleos de baja calidad y bajos salarios. En términos relativos el cambio más destacado fue el rápido crecimiento de la construcción, que duplicó ampliamente su cifra de empleos (de 160,8 a 324,8 miles) hasta representar un 10,7\% del empleo total como reflejo de la burbuja financiera e inmobiliaria que también creció en Madrid, apoyada por un planeamiento urbanístico flexible y acorde con los intereses de la coalición hegemónica (Observatorio Metropolitano, 2009). Los trabajadores de menor cualificación, vinculados a las actividades de baja productividad, se localizaron de forma mayoritaria en los sectores del sur y este metropolitanos, reforzando en términos cualitativos la segmentación territorial ya señalada.

Mucho se ha escrito sobre las externalidades positivas asociadas a la aglomeración y a la concentración de capital físico, humano, financiero, relacional, institucional y cognitivo que suele acompañarle, generadora de ventajas competitivas duraderas para las grandes metrópolis en el actual contexto de mundialización y Madrid pareció durante algunos años un ejemplo significativo para ese discurso dominante (Glaeser, 2011). Pero la crisis iniciada en 2007 ha obligado a recordar las profundas contradicciones existentes en su interior y las vulnerabilidades derivadas de una urbanización neoliberal que ahora se reflejan en los negativos impactos económicos, sociales o laborales provocados, la profundización de las desigualdades espaciales y un cuestionamiento de las formas de gobernanza y gestión vigentes. Entre esas múltiples manifestaciones de una crisis sistémica, aquí se centrará la atención en las de carácter laboral y en su reflejo sobre el territorio metropolitano.

\section{Impactos de la crisis en el mercado de trabajo de Madrid}

En el periodo comprendido entre el último trimestre de 2006 y el de 2014, los principales indicadores laborales de la región metropolitana madrileña mostraron una evolución negativa, haciendo patente la intensidad de los procesos de desposesión (Tabla 1). En estos ocho años, el número de ocupados se redujo en casi 300.000 $(-9,6 \%)$ y ese retroceso fue espectacular en la construcción, que perdió la mitad de sus empleos hasta representar sólo un 4,8\% del total en 2014. La paralela intensificación del proceso desindustrializador, con un sector que ya ocupa a menos de una décima parte $(9,2 \%)$ de los trabajadores metropolitanos, ha acentuado una hiperespecialización terciaria $(85,6 \%)$ que atenta contra la diversificación de las economías metropolitanas y su capacidad de innovación. 
Tabla 1 - Evolución del mercado de trabajo en la región metropolitana de Madrid y España, 2006-2014

\begin{tabular}{l|c|c|c|c|c|c}
\hline \multicolumn{1}{c|}{ Indicador } & $\begin{array}{c}\text { Madrid } \\
\text { 2006 (miles) }\end{array}$ & $\begin{array}{c}\text { Madrid } \\
\text { 2014 (miles) }\end{array}$ & $\begin{array}{c}\text { España } \\
\text { 2006 (miles) }\end{array}$ & $\begin{array}{c}\text { España } \\
\text { 2014 (miles) }\end{array}$ & $\begin{array}{c}\text { Madrid } \\
\text { 2006-14 (\%) }\end{array}$ & $\begin{array}{c}\text { España } \\
\text { 2006-14 (\%) }\end{array}$ \\
\hline Ocupados & $3.085,3$ & $2.789,0$ & $20.195,4$ & $17.569,1$ & $-9,60$ & $-13,0$ \\
Desempleados & 209,4 & 612,3 & $1.942,0$ & $5.457,7$ & 192,41 & 181,03 \\
Desempleo juvenil (<25 años) & 62,1 & 102,5 & 435,8 & 813,7 & 65,06 & 86,71 \\
Desempleo mujeres & 128,6 & 291,5 & $1.043,8$ & $2.634,0$ & 126,67 & 152,35 \\
Desempleo de larga duración & 45,9 & 379,4 & 454,5 & $3.352,9$ & 726,58 & 637,71 \\
Paro registrado & 211,6 & 498,6 & $2.022,9$ & $4.447,7$ & 135,63 & 119,87 \\
Beneficiarios de prestaciones & 133,7 & 278,8 & $1.330,4$ & $2.543,0$ & 108,53 & 91,14 \\
Población en riesgo pobreza (\%) & 14,9 & 19,2 & 24,0 & 29,2 & 28,86 & 21,67 \\
\hline
\end{tabular}

Fuentes: INE. Encuesta de Población Activa ( $4^{\circ}$ trimestre) y Encuesta de Condiciones de Vida; SEPE. Movimiento Laboral Registrado (diciembre) y Estadística de Prestaciones.

Pero el sostenido aumento de la población activa ha provocado que la cifra de desempleados según la Encuesta de Población Activa creciera en 403.000 personas (Figura 5), triplicando su volumen en $2006(+192,4 \%)$. Aunque mantienen tasas superiores al promedio, el aumento del desempleo entre las mujeres $(+126,7 \%)$ y los jóvenes $(+65,1 \%)$ fue inferior; en el primer caso, porque las ocupaciones más golpeadas por la crisis (construcción, industria) contaban con un neto predominio de trabajadores masculinos, situación que se moderó al difundirse la destrucción de empleos a los servicios al consumo, más feminizados; en el segundo, porque muchos jóvenes prolongaron sus estudios o se han mantenido al margen del mercado laboral ante la dificultad de incorporación.

Algo menor fue el incremento del paro registrado $(+135,6 \%)$, que sólo considera a las personas inscritas en las oficinas públicas de empleo, pues las escasas oportunidades de encontrar trabajo aumentaron el número de los desanimados y la prolongación de la recesión agotó el tiempo máximo para recibir una prestación por desempleo, por lo que muchas personas dejaron de acudir. La gravedad de este problema queda patente al considerar que el paro de larga duración, más de un año, se multiplicó por ocho $(+726,6 \%)$ y que los beneficiarios de prestaciones por desempleo tan sólo se duplicaron $(+108,5 \%)$, rebajando la tasa de cobertura a apenas un $50 \%$ del total. El aumento de la población en riesgo de pobreza y exclusión que, según los criterios aplicados en la Unión Europea (menos del $60 \%$ de la mediana de ingresos), afecta ya a casi una quinta parte de los residentes en Madrid $(19,2 \%)$ tiene aquí una de sus principales causas. 
Figura 5 - Evolución del desempleo en la región metropolitana de Madrid, 2006-14

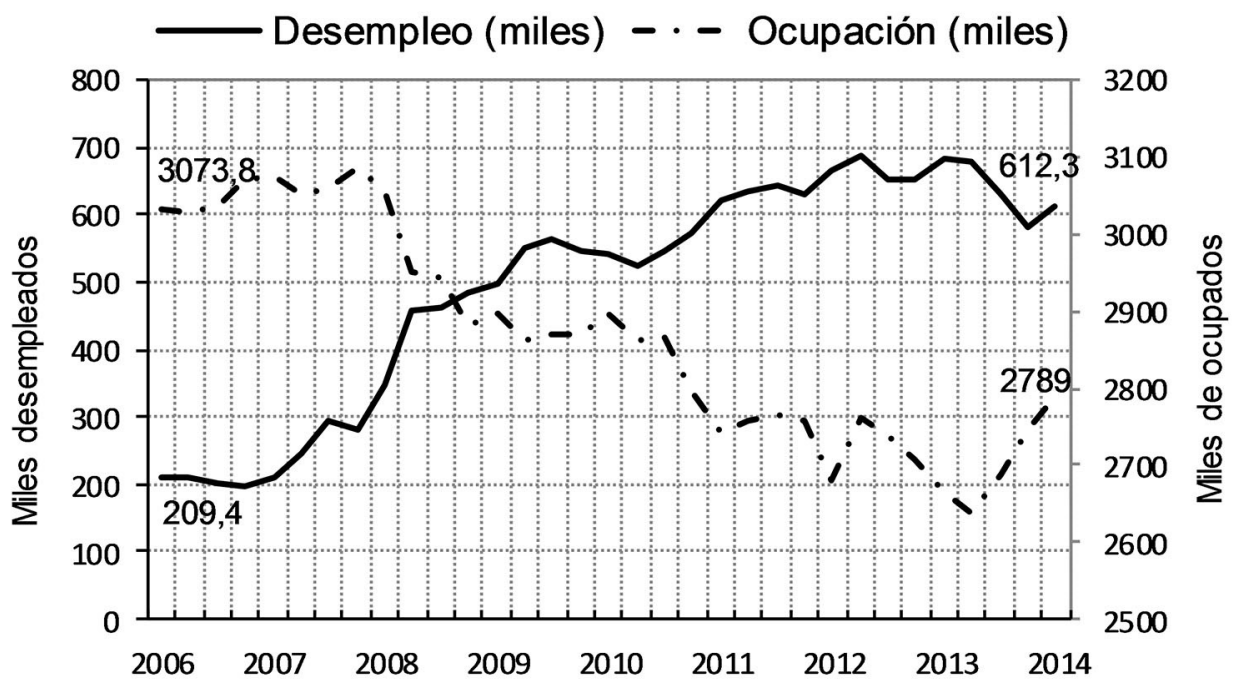

Fuente: Instituto Nacional de Estadística. Encuesta de Población Activa (trimestral).

Pero los datos de la tabla muestran que hasta en cinco de los ocho indicadores analizados el impacto de la crisis en la región metropolitana de Madrid superó el promedio español. Se confirma así que el modelo de crecimiento económico y generación de empleo asociado, sobre todo, al auge financiero e inmobiliario conllevó una elevada exposición al riesgo y un aumento de la vulnerabilidad para amplios grupos sociales y laborales poco cualificados y progresivamente desprotegidos, con efectos inmediatos tras el estallido de la crisis. Aunque el moderado aumento del empleo iniciado en 2014 resulta en Madrid algo más intenso y puede relacionarse con cierta recuperación del cluster financiero-inmobiliario y del consumo interno, las debilidades apuntadas siguen siendo evidentes.

Este ambiente de crisis resultó también propicio para deteriorar las condiciones laborales, aunque la información disponible a esta escala limita las posibilidades del análisis. Puede señalarse, no obstante, que los 2,6 millones de contratos firmados en 2006 se redujeron a 1,7 desde 2009 para recuperarse levemente en 2014 (1,9 millones). Pero si en 2006 la proporción de contratos temporales sobre el total era del $82,3 \%$, aún creció ligeramente durante los años de crisis, alcanzando un máximo del 86,4\% en 2011 para quedar en un 84,2\% en 2014 (Tabla 2). 
Tabla 2 - Evolución de los contratos firmados

en la región metropolitana de Madrid, 2006-2014

\begin{tabular}{|c|c|c|c|c|c|c|c|c|c|}
\hline Indicadores & 2006 & 2007 & 2008 & 2009 & 2010 & 2011 & 2012 & 2013 & 2014 \\
\hline Miles de contratos & $2.570,1$ & $2.551,8$ & $2.167,2$ & $1.660,4$ & $1.714,7$ & $1.727,2$ & $1.712,2$ & $1.671,0$ & $1.887,0$ \\
\hline$\%$ indefinidos & 17,7 & 19,3 & 19,1 & 15,8 & 14,7 & 13,6 & 19,6 & 15,4 & 15,8 \\
\hline$\%$ temporales & 82,3 & 80,7 & 80,9 & 84,2 & 85,3 & 86,4 & 80,4 & 84,6 & 84,2 \\
\hline
\end{tabular}

Fuente: Sociedad Pública de Empleo Estatal. Movimiento Laboral Registrado.

En resumen, el mercado de trabajo madrileño ha padecido un profundo deterioro que se hizo patente con la crisis, pero cuyas raíces se alimentaron en la fase de crecimiento. Del mismo modo, la segmentación sociolaboral del territorio metropolitano, que ya era evidente en un contexto expansivo, ha intensificado sus rasgos en la reciente fase recesiva.

\section{Crisis, vulnerabilidad sociolaboral y contrastes en la región metropolitana}

Pese a considerar un conjunto de núcleos urbanos que se sitúan a menos de 30 kilómetros de la ciudad de Madrid, la intensidad del impacto provocado por la crisis sobre sus mercados locales de trabajo ha sido muy desigual, lo que puede relacionarse con su mayor o menor vulnerabilidad específica.

Ante las importantes carencias de información estadística a esta escala, el análisis se ha limitado a cuatro indicadores que reflejan lo ocurrido entre el final de 2006 y 2014 desde perspectivas complementarias: la evolución de la ocupación y el paro registrado, la proporción de contratos temporales sobre el total de los firmados en esos años y, por último, el crecimiento del número de los solicitantes de una renta mínima de inserción por haber agotado la prestación por desempleo y no disponer de ningún ingreso. La Tabla 3 resume esos contrastes, agrupando los municipios según su localización en los diferentes sectores de la región metropolitana. Desde hace décadas, en ese territorio se dibujó una división social y funcional entre los sectores más valorados del norte y, más aún, del oeste, frente a una concentración de los grupos socioprofesionales menos cualificados, de menores ingresos y más precarios en los sectores sur y este, que la crisis ha profundizado en los últimos años.

Así, frente a un descenso medio de la ocupación del $-7,82 \%$, la práctica totalidad de los núcleos meridionales y orientales de la aglomeración registraron pérdidas superiores, con valores extremos en Pinto $(-36,38 \%)$ y Fuenlabrada $(-29,51 \%)$. Por el contrario, todos los núcleos occidentales salvo los localizados a mayor distancia vieron aumentar su empleo al ubicarse en ellos buena parte de los parques empresariales, comerciales y de ocio promovidos en las dos últimas décadas, junto a numerosos centros escolares, universitarios y sanitarios privados, con Boadilla del Monte $(33,27 \%)$ como mejor exponente. Pese a todo, 
Tabla 3 - Evolución de indicadores sociolaborales en municipios madrileños con más de 25.000 habitantes, 2006-2014

\begin{tabular}{|c|c|c|c|c|}
\hline Municipios & $\begin{array}{l}\text { Población ocupada } \\
\qquad\left(^{*}\right)\end{array}$ & $\begin{array}{l}\text { Paro registrado } \\
\left({ }^{* *}\right)\end{array}$ & $\begin{array}{c}\% \text { Contratos } \\
\text { temporales } \\
\left({ }^{* *}\right)\end{array}$ & $\begin{array}{l}\text { Solicitantes renta } \\
\text { mínima inserción } \\
\qquad\left(*^{* *}\right)\end{array}$ \\
\hline Ciudad de Madrid & $-12,29$ & 131,55 & 82,74 & 146,59 \\
\hline \multicolumn{5}{|l|}{ Norte Metropolitano } \\
\hline Alcobendas & 3,47 & 176,41 & 79,61 & 354,29 \\
\hline Colmenar Viejo & $-16,87$ & 246,06 & 81,02 & 766,67 \\
\hline San Sebastián de los Reyes & $-5,69$ & 195,46 & 83,92 & 357,14 \\
\hline Tres Cantos & 4,25 & 139,09 & 85,70 & 150,00 \\
\hline \multicolumn{5}{|l|}{ Oeste Metropolitano } \\
\hline Boadilla del Monte & 33,27 & 145,18 & 79,93 & 350,00 \\
\hline Collado Villalba & $-7,41$ & 183,45 & 79,31 & 254,05 \\
\hline Galapagar & $-18,58$ & 161,10 & 76,87 & 75,68 \\
\hline Majadahonda & 20,45 & 136,23 & 77,93 & 266,67 \\
\hline Pozuelo de Alarcón & 14,18 & 113,52 & 77,77 & 537,50 \\
\hline Rozas (Las) & 24,02 & 143,14 & 76,63 & 640,00 \\
\hline \multicolumn{5}{|l|}{ Este Metropolitano } \\
\hline Alcalá de Henares & $-15,75$ & 147,13 & 87,85 & 247,46 \\
\hline Arganda del Rey & $-17,62$ & 288,45 & 85,66 & 270,59 \\
\hline Coslada & $-17,21$ & 156,23 & 85,80 & 500,00 \\
\hline Rivas-Vaciamadrid & $-3,47$ & 229,52 & 84,04 & 253,57 \\
\hline San Fernando de Henares & $-7,87$ & 190,26 & 81,69 & 433,33 \\
\hline Torrejón de Ardoz & $-20,18$ & 209,62 & 83,54 & 369,35 \\
\hline \multicolumn{5}{|l|}{ Sur Metropolitano } \\
\hline Alcorcón & $-15,16$ & 122,21 & 84,15 & 579,07 \\
\hline Aranjuez & $-9,36$ & 192,74 & 89,70 & 188,37 \\
\hline Fuenlabrada & $-29,51$ & 170,76 & 83,04 & 740,00 \\
\hline Getafe & $-10,06$ & 138,20 & 87,44 & 269,30 \\
\hline Leganés & $-11,88$ & 149,90 & 84,30 & 338,79 \\
\hline Móstoles & $-26,19$ & 130,96 & 82,54 & 413,33 \\
\hline Navalcarnero & $-10,38$ & 270,29 & 86,08 & 305,56 \\
\hline Parla & $-11,74$ & 254,65 & 82,86 & 1392,16 \\
\hline Pinto & $-36,38$ & 243,73 & 86,20 & 335,29 \\
\hline Valdemoro & $-7,86$ & 186,36 & 84,40 & 571,43 \\
\hline Villaviciosa de Odón & $-7,20$ & 113,83 & 83,86 & 425,00 \\
\hline Promedio & $-7,82$ & 177,36 & 83,02 & 411,83 \\
\hline Desviación estándar & 15,66 & 49,22 & 3,39 & 258,12 \\
\hline
\end{tabular}

Fuentes: $\left({ }^{*}\right)$ Instituto Nacional de Estadística $\left({ }^{* *}\right)$ Sociedad Pública de Empleo Estatal $\left(^{* * *}\right)$ Consejería de Asuntos Sociales de la Comunidad de Madrid. 
el aumento del paro registrado (177,36\% en promedio) afectó a todos los municipios metropolitanos, pero de nuevo los incrementos por encima del $250 \%$ correspondieron a núcleos del sur (Navalcarnero, Parla) y este (Arganda del Rey), con mayor presencia de los grupos de riesgo, frente a valores bastante inferiores en los del oeste, con Pozuelo de Alarcón (113,52\%) en el extremo opuesto de la escala.

A su vez, si un $83 \%$ de los contratos firmados durante la crisis fueron temporales esa proporción resultó inferior al $80 \%$ en los núcleos occidentales (además de Alcobendas, en el norte), con un valor mínimo del 76,63\% en Las Rozas, frente a cifras de nuevo superiores al promedio en casi todos los del sur y este, con Aranjuez (89,70\%) a la cabeza. Finalmente, los solicitantes al gobierno autonómico de la Renta Mínima de Inserción (RMI) se quintuplicaron en estos ocho años $(411,83 \%)$, pero si bien en este caso hay claves locales que introducen cierta complejidad en un esquema dual que simplifica la realidad, los contrastes y las regularidades espaciales vuelven a ser evidentes, con valores extremos en el municipio sureño de Parla (1.392,16\%) frente al occidental de Galapagar (75,68\%).

Los mapas de las Figuras 6 y 7 reflejan de forma gráfica la desigual vulnerabilidad ante la crisis en dos de estos indicadores (paro y solicitantes de RMI) al agrupar a los 28 municipios según su tasa de crecimiento. Cuando supera la tasa promedio más una desviación estándar se califica de crecimiento muy alto, se identifica como alto cuando sólo logra superar el promedio, es un crecimiento bajo cuando está por debajo de ese nivel y muy bajo si esa diferencia negativa es mayor que una desviación estándar. Se confirma así que la distribución espacial no es en absoluto aleatoria sino que se asocia con el sector metropolitano y la distancia a la ciudad central, además de factores locales que matizan esa regularidad geométrica. Pero también se comprueba que la ciudad de Madrid se sitúa siempre en valores intermedios, debido a que en su interior se reproducen los contrastes entre los barrios del noroeste y sureste, sólo visibles para una escala de análisis no considerada en este artículo.

\section{Comentarios finales}

El mercado de trabajo en la región metropolitana de Madrid enfrenta en los últimos años una situación particularmente grave en que a las altas tasas de paro se suman la difusión de la precariedad a un número creciente de actividades y ocupaciones, el deterioro de los salarios reales y una intensificación de los contrastes territoriales internos. Estos fenómenos son manifestaciones de un proceso general de desposesión que se manifiesta con especial intensidad en los periodos de crisis como la iniciada en 2007 y que, al ser respondida con políticas de austeridad fiscal y reformas estructurales de clara inspiración neoliberal, acentuó sus efectos.

Pero frente al discurso que pretende situar esa crisis en el origen del deterioro padecido por las condiciones laborales, aquí se ha defendido que la influencia del régimen de acumulación financiarizado sobre las economías metropolitanas y del modo de regulación neoliberal en la flexibilización/precarización del mercado de trabajo crearon desde hace varias 
Figura 6 - Crecimiento del paro registrado en municipios $>25.000$ habs de la región metropolitana de Madrid, 2006-2014

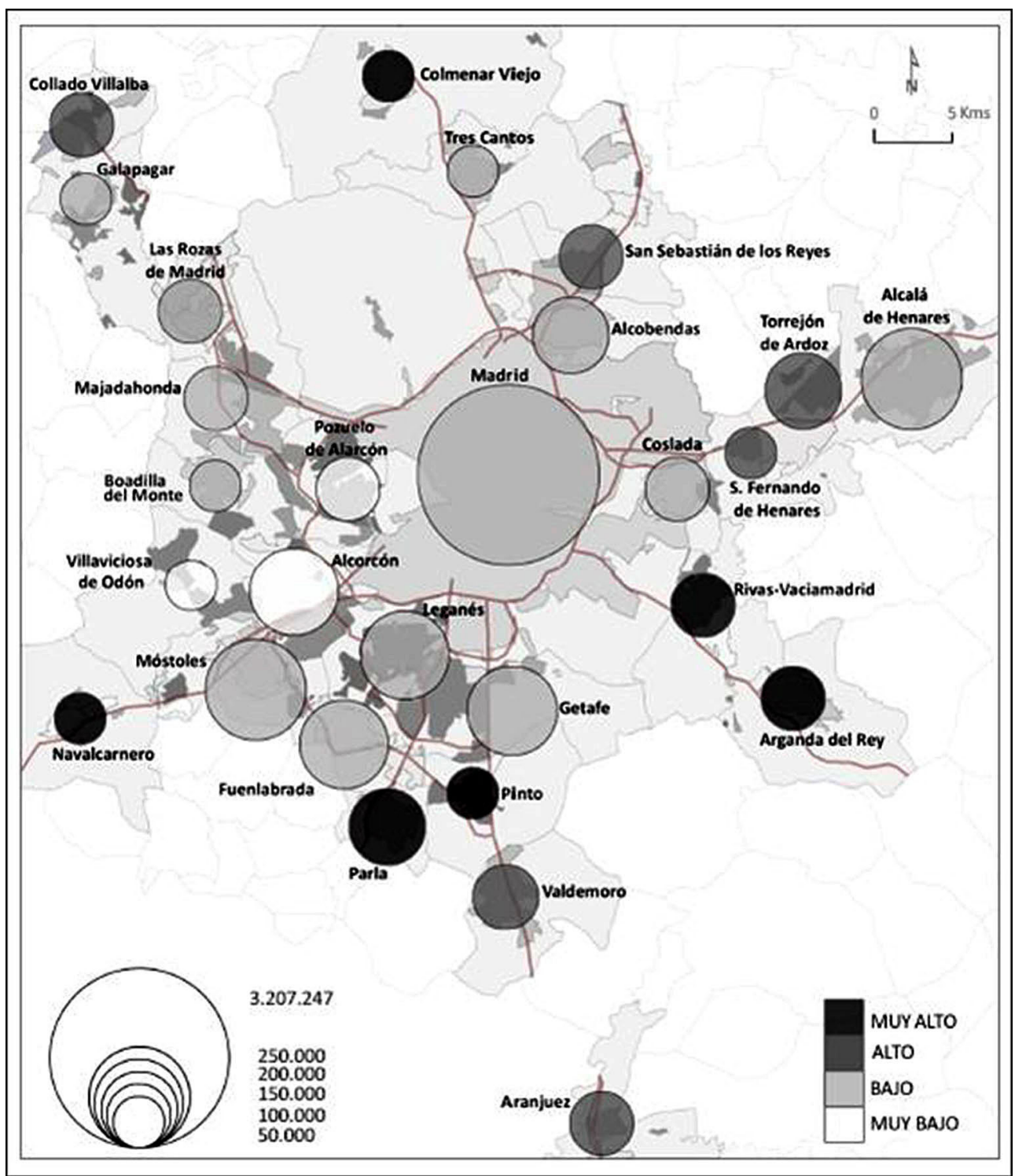

Fuente: Instituto de Estadística de la Comunidad de Madrid. Banco de Datos Municipal y elaboración propia. 
Figura 7 - Crecimiento de solicitantes de la renta mínima de inserción en municipios >25.000 habs. de la región metropolitana de Madrid, 2006-2014

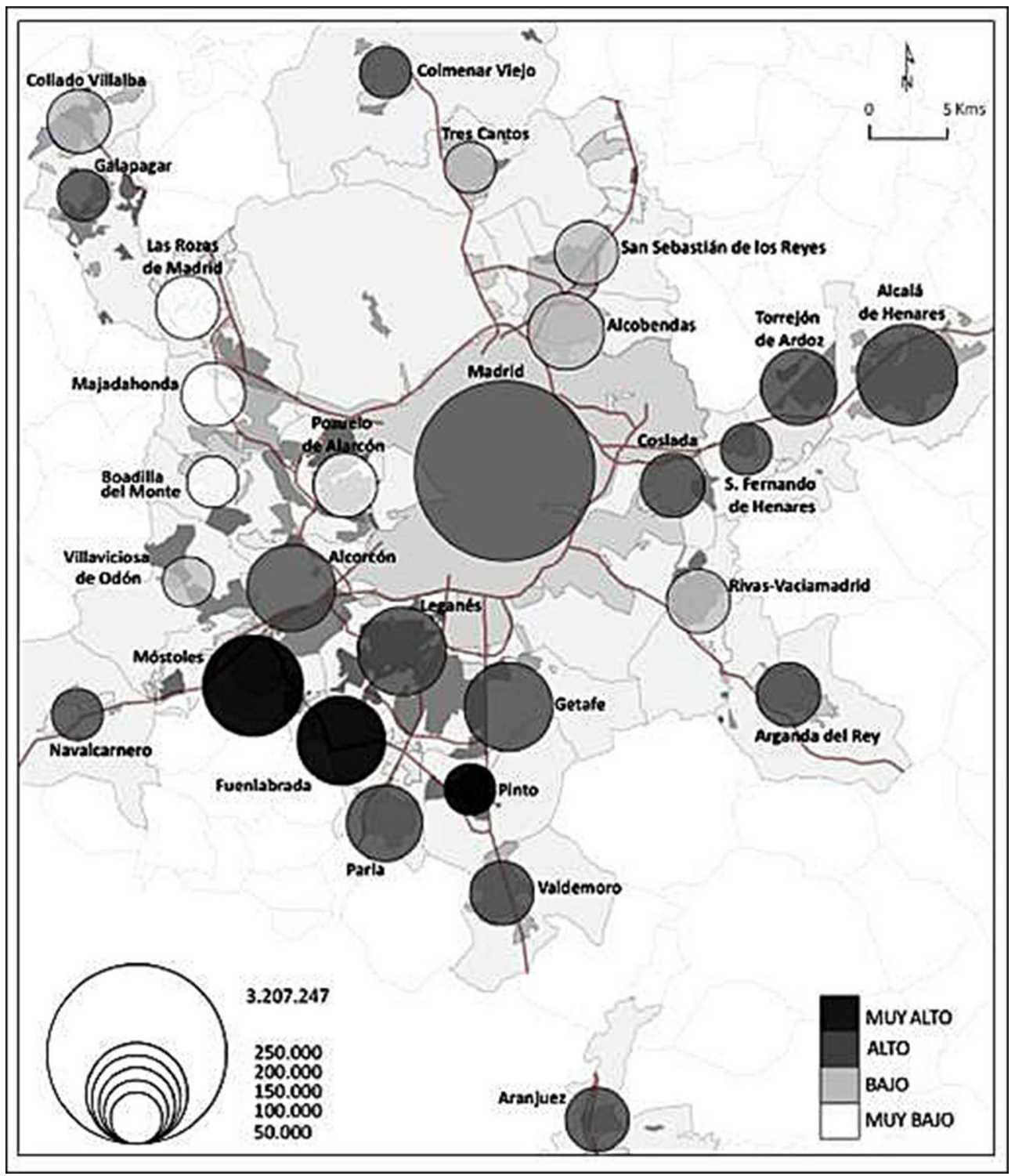

Fuente: Instituto de Estadística de la Comunidad de Madrid. Banco de Datos Municipal y elaboración propia. 
décadas el marco adecuado para que ese deterioro fuera luego particularmente rápido e intenso. Las economías, las sociedades y los territorios metropolitanos se hicieron así más vulnerables por su mayor exposición al riesgo, lo que afectó de modo directo a la calidad de su empleo, más aún en aquellos ámbitos donde una gobernanza corporativa favorable a los intereses de la coalición inmobiliario-financiera fue claramente hegemónica. Pero esa vulnerabilidad genérica resultó aún mayor en aquellos sectores y núcleos metropolitanos donde, en el transcurso del proceso urbanizador y siguiendo la lógica del mercado, se concentraron aquellos grupos sociales y colectivos laborales más frágiles, que son los que han pagado buena parte de los costes derivados del agotamiento de ese modelo de crecimiento.

Si comprender las claves de esta crisis que ha golpeado con fuerza a la región metropolitana de Madrid - pese a contar con una serie de ventajas competitivas que parecían inmunizarla - exige una perspectiva multiescalar que combine la influencia de los procesos globales y los actores locales, lo mismo ocurre a la hora de plantear posibles soluciones.

Sin pretender entrar aquí en una propuesta de acciones específicas, parece evidente que desde la escala metropolitana se necesita reorientar la economía para frenar su deriva financiero-inmobiliaria y su excesiva orientación hacia el consumo mediante estrategias que permitan recuperar cierto volumen de actividades productivas renovadas, incrementar el esfuerzo innovador en todo tipo de sectores y empresas, apoyar aquellos servicios que son intensivos en conocimiento, así como el creciente número de iniciativas que surgen en el ámbito de la economía social y solidaria. Se necesita también un cambio de prioridades que sitúe el objetivo de generar más y, a la vez, mejor empleo como base para la necesaria renovación de un discurso sobre las metrópolis globales que, más allá de su capacidad competitiva, se plantee el reto de hacerlas menos vulnerables y más inclusivas. Del mismo modo, deben ponerse en marcha unas directrices de ordenación territorial que limiten la creciente segmentación funcional y sociolaboral del espacio inherente al modelo de urbanización de las últimas décadas, que la crisis ha acentuado hasta límites insostenibles.

Pero también se necesitan políticas de más amplio alcance cuyo ámbito de decisión son las instituciones europeas y españolas, capaces de cuestionar una racionalidad neoliberal y una mercantilización del desarrollo urbano que están en la raíz de lo ocurrido. Recuperar el valor del trabajo y sus derechos, reforzar los mecanismos redistributivos en el reparto del excedente y los procesos participativos que están en la base del pacto social, son algunas claves para una evolución que sólo la presión social y sindical hará posible.

Hace ahora un cuarto de siglo, en el prólogo de un libro sobre las transformaciones que experimentaban las grandes ciudades y sus entornos en un contexto de revolución tecnológica y cambio productivo, pero también de creciente hegemonía del pensamiento y la práctica neoliberales, se afirmaba que estas constituyen "una forma social y espacial de convivencia en la que se refleja lo mejor y lo peor de nuestras sociedades, el 
dinamismo económico y la creatividad cultural junto a los problemas urbanos, sociales y medioambientales más agudos" (Borja et al., 1990, p. 8). Los mercados de trabajo metropolitanos constituyen una buena síntesis de muchas de esas transformaciones recientes y su crisis refleja con claridad los límites del modelo de globalización neoliberal de las últimas décadas. En ese equilibrio siempre inestable entre beneficios y costes asociados a estas grandes concentraciones humanas, la defensa de los derechos de ciudadanía sigue exigiendo situar la acción colectiva en pro de mejores condiciones laborales como una de las claves para hacer posible la construcción de espacios metropolitanos resilientes tras la crisis, lo que no sólo supone recuperar la actividad y el empleo, sino también avanzar hacia un mejor desarrollo en que la cohesión y la sostenibilidad sean valores a defender.

\section{Ricardo Méndez}

Centro de Ciencias Humanas y Sociales, Instituto de Economía, Geografía y Demografía, Departamento de Economía y Geografía Aplicadas. Consejo Superior de Investigaciones Científicas. ricardo.mendez@cchs.csic.es

\section{Nota}

(1) La Comunidad de Madrid, con un territorio de 8.022 kilómetros cuadrados, está dividida en 179 municipios con gobierno local propio. De ellos, 28 superan los 25.000 habitantes y se sitúan en las coronas metropolitanas más próximas a la ciudad capital ( $<30 \mathrm{kms})$, por lo que pueden considerarse el área urbana consolidada, que será objeto de estudio y concentra más de tres cuartas partes de la población y el empleo, rodeada por una franja periurbana que supera los límites administrativos y se extiende por otras comunidades limítrofes.

\section{Referências}

AALBERS, M. B. (2008). The financialization of home and the mortgage market crisis. Competition \& Change, v. 12 , n. 2, pp. 148-166.

ALGUACIL, J.; CAMACHO, J. y HERNÁNDEZ AJA, A. (2014). La vulnerabilidad urbana en España. Identificación y evolución de los barrios vulnerables. Empiria - Revista de Metodología de Ciencias Sociales, n. 27, pp. 73-94.

ALONSO, L. E. y FERNÁNDEZ, C. J. (eds.) (2012). La financiarización de las relaciones salariales. Una perspectiva internacional. Madrid, Los Libros de la Catarata-FUHEM. 
BALES, K. (2000). Disposable people. New slavery in the global economy. Berkeley, University of California Press.

BATHELT, H. y GLÜCKLER, J. (2013). Institutional change in economic geography. Progress in Human Geography, n. 38, pp. 340-363.

BECK, U. (2000). Un nuevo mundo feliz. La precariedad del trabajo en la era de la globalización. Barcelona, Paidós.

BOLTANSKI, L. y CHIAPELLO, E. (2002). El nuevo espíritu del capitalismo. Madrid, Akal.

BORJA, J. et al. (eds.) (1990). Las grandes ciudades en la década de los noventa. Madrid, Editorial Sistema.

CASTEL, R. (1997). La metamorfosis de la cuestión social. Buenos Aires, Paidós.

CHESNAIS, F. (2003). La teoría del régimen de acumulación financiarizado: contenido, alcance e interrogantes. Revista de Economía Crítica, n. 1, pp. 37-72.

DAHER, A. (2013). El sector inmobiliario y las crisis económicas. Eure - Revista Latinoamericana de Estudios Urbanos y Regionales, v. 39, n. 118, pp. 47-76. Disponible en: http://www.scielo.cl/ scielo.php?pid=S0250-71612013000300003\&script=sci_arttext.

GLAESER, E. (2011). El triunfo de las ciudades. Madrid, Taurus.

HALBERT, L. (2005). Les métropoles, moteurs de la dematerialisation du système productif urbain français: une lecture sectorielle et fonctionelle (1982 à 1999). Bulletin de l'Association des Géographes Françaises, v. 82, n. 3, pp. 277-299.

HARVEY, D. (2004). El nuevo imperialismo. Madrid, Akal.

(2007). Espacios del capital. Hacia una geografía crítica. Madrid, Akal.

HIDALGO, R. y JANOSCHKA, M. (eds.) (2014). La ciudad neoliberal. Gentrificación y exclusión en Santiago de Chile, Buenos Aires, Ciudad de México y Madrid. Santiago de Chile, Pontificia Universidad Católica de Chile.

LAVAL, C. y DARDOT, P. (2013). La nueva razón del mundo. Ensayo sobre la sociedad neoliberal. Barcelona, Gedisa.

MARTIN, R. (2011). The local geographies of the financial crisis: from the housing bubble to economic recession and beyond. Journal of Economic Geography, v. 11, n. 4, pp. 587-618.

MCDOWELL, L. y CHRISTOPHERSON, S. (2009). Transforming work: new forms of employment and their regulation. Cambridge Journal of Regions, Economy and Society, n. 2, pp. 335-342.

MÉNDEZ, R. (2013). Crisis económica, vulnerabilidad y desempleo en España. Ciudad y Territorio Estudios Territoriales, v. XLV, n. 178, pp. 649-667.

MÉNDEZ, R.; ABAD, L. D. y ECHAVES, C. (2015). Atlas de la crisis. Impactos socioeconómicos y territorios vulnerables en España. Valencia, Tirant lo Blanch.

MÉNDEZ, R.; ONDÁTEGUI, J. y SÁNCHEZ MORAL, S. (2007). “La estructura territorial de las actividades económicas y la renta”. In: GARCíA DELGADO, J. L. (dir.). Estructura económica de Madrid. Madrid, Comunidad de Madrid-Thomson Civitas.

OBSERVATORIO METROPOLITANO (2009). Manifiesto por Madrid. Crítica y crisis del modelo metropolitano. Madrid, Traficantes de Sueños. 
OCDE (2007). Territorial Reviews. Madrid, Spain, París, OCDE.

PECK, J. y THEODORE, N. (2010). "Labour markets from the bottom-up”. In: MCGRATH-CHAMP, A.; HEROD, A. y RANNIE, A. (eds.). Working space: handbook of employment and society. Cheltenham, Edward Elgar.

PRATSCHKE, J. y MORLICCIO, E. (2012). Social polarisation, the labour market and economic restructuring in Europe: an urban perspective. Urban Studies, v. 49, n. 9, pp. 1891-1907.

RECIO, A. y BANYULS, J. (2011). Crisis y modelos nacionales de empleo; la experiencia de diez países europeos en la crisis. Revista de Economía Crítica, n. 11, pp. 173-184. Disponible en: http://revistaeconomiacritica.org/sites/default/files/revistas/n11/ REC11_7_AlbertRecio_ JosephBanyuls.pdf.

RIFKIN, J. (1996). El fin del trabajo: nuevas tecnologías contra puestos de trabajo. El nacimiento de una nueva era. Barcelona, Paidós.

ROCHA, F. (coord.) (2010). El mercado de trabajo en España en 2014. Una recuperación insuficiente y precaria. Informes, n. 116, Fundación 1ㅇ de Mayo. Disponible en: http://www.1mayo.ccoo.es/ nova/files/1018/Informe116.pdf.

SÁNCHEZ MORAL, S. (2011). "Iberian cities". In: TAYLOR, P. J. et al. (eds.). Global urban analysis. A survey of cities in globalization. Londres-Washington, Earthscan.

SANCHÍs, E. (2012). El drama del paro. Anuario 2012. Madrid, Fundación 1o de Mayo, pp. 287-297. Disponible en: http://www.1mayo.ccoo.es/ nova/files/1018/Portada201204.pdf.

SERVICIO DE ESTUDIOS F1M (2014a). Informe Trabajo Decente 2014. Diagnóstico y reflexiones sobre la precariedad en España. Informes, n. 105, Fundación 1ㅇ de Mayo. Disponible en: http:// www.1mayo.ccoo.es/nova/files/1018/Informe105.pdf.

(2014b). Pobreza y trabajadores pobres en España. Informes, n. 106, Fundación 1o de Mayo. Disponible en: www.1mayo.ccoo.es/nova/files/1018/Informe106.pdf.

SENNETT, R. (2000). La corrosión del carácter. Las consecuencias personales del trabajo en el nuevo capitalismo. Barcelona, Anagrama.

STANDING, G. (2013). El precariado. Una nueva clase social. Barcelona, Pasado \& Presente.

SUBIRATS, J. y MARTÍ-COSTA, M. (eds.) (2014). Ciudades, vulnerabilidades y crisis en España. Sevilla, Fundación Pública Andaluza Centro de Estudios Andaluces. Disponible en: https://www. centrodeestudiosandaluces.es/ datos/factoriaideas/IFO02_14.pdf.

WILLS, J. (2009). Subcontracted employment and its challenge to labor. Labor Studies Journal, n. 34, pp. 441-460.

Texto recebido em 22/ago/2016

Texto aprovado em 26/nov/2016 